\title{
JAK2 NM_004972.3:C.2624C>A
}

National Cancer Institute

\section{Source}

National Cancer Institute. AKK2 NM 004972.3:C.2624C>A. NCI Thesaurus. Code

C116965.

A nucleotide substitution at position 2624 of the coding sequence of the JAK2 gene where cytosine has been mutated to adenine. 